\title{
LA REVUELTA POLACA DE 1956
}

\author{
Jan Stanisław Ciechanowski \\ Instituto de Investigaciones Interdisciplinares \\ "Artes Liberales". Universidad de Varsovia
}

RESUMEN: Después de la muerte de Stalin en marzo de 1953 empezó el lento proceso de la salida de las dictaduras comunistas, controladas por Moscú, de su época más dura Ilamada estalinista. Estos cambios ocurrieron también en Polonia, donde disminuyó el terror y terminó la sovietización del país. El partido comunista estaba en crisis. La tensión social estalló cuando en junio de 1956 los obreros declararon la huelga general y salieron a las calles de Poznań. Pronto una protesta económica se convirtió en anticomunista bajo el lema "pan y libertad". La manifestación terminó en lucha armada. La cúpula comunista decidió reprimir el levantamiento de una manera sangrienta, usando con este fin al ejército. A junio de 1956 le siguieron las protestas de octubre de ese mismo año, con sus lemas liberalizadores y antisoviéticos que terminaron con cierta liberalización del régimen.

Palabras clave: Polonia, sublevación polaca, comunismo polaco, democracia polaca, movimiento obrero.

ABSTRACT: After the death of Stalin in March 1953 started a slow process of passing by the Communist dictatorships, controlled by Moscow, from its most severe period (called Stalinist) to a more liberalized one. These changes occurred also in Poland, where a terror diminished and the sovietization of the country finished. The Communist Party was in crisis. The social tension broke out when in June 1956 the workers declared a general strike and went out to the streets of Poznań. In a short time an economic protest converted in an anti-Communist one under a slogan "bread and freedom". The manifestation ended in armed struggle. The Communist leaders decided to suppress the uprising in blood, using the army with that aim. After the June 1956 the protests of October of that year 
came with its liberalizing and anti-Soviet slogans which ended with a certain liberalization of the regime.

Keywords: Poland, Polish uprising, Polish communism, Polish democracy, Labor movement.

\section{Antecedentes}

En 1945 Polonia perdió su independencia. Los fines y la política del nuevo Estado-satélite fueron subordinados a los intereses soviéticos. El dominio de Moscú no supuso más que la continuación del imperialismo ruso, imperialismo no en el sentido peyorativo y vulgar que se usaba a menudo, sino como un proyecto de extender las fronteras rusas, disfrazado esta vez muy hábilmente por una ideología atractiva para numerosos círculos de extrema izquierda fuera de la URSS. De algún modo se repetía la situación de los años 1815-1830, cuando los rusos, partícipes de los repartos del Estado polaco independiente, crearon una especie de Reino de Polonia bajo el zar de Rusia, reino considerado simplemente por los polacos como una forma de ocupación de la que dieron constancia en el gran levantamiento de 1830-1831. Con la llegada al poder de los bolcheviques, la tradicional política rusa contra Polonia sólo se agravó, basándose en los mismos principios de intentar controlar a la nación vecina. Un momento clave lo encontramos en la gran victoria del Ejército polaco mandado por Józef Piłsudski, el padre de la independencia, contra las tropas soviéticas en 1920. Un éxito que salvó la independencia de Polonia, no dejando que se juntasen los revolucionarios comunistas de Rusia y Alemania para llevar la tea incendiaria del golpismo soviético a toda Europa occidental y que aumentó la aversión de Moscú contra la Polonia "blanca"1.

Durante el periodo de entreguerras la República polaca, una creación del Tratado de Versalles, intentaba sin resultado disminuir la constante amenaza por el este y oeste para su seguridad. A finales de agosto de 1939, los dos vecinos, Alemania y la Unión Soviética, sellaron un pacto, realmente una especie de alianza entre el nazismo y el comunismo, que consistía en empezar la guerra contra el Estado polaco y repartirse los territorios en Europa Central y Oriental. El 1 de septiembre Alemania atacó a Polonia, cuyas autoridades antes habían decidido mantener su independencia por encima de todo negándose a participar junto a Hitler en su invasión contra la Rusia soviética. El 17 del mismo mes la URSS invadió Polonia oriental, tal y como fue acordado en el pacto Ribbentrop-Molotov, ocupando cerca del 52\% de su territorio con 13 millones de habi-

1. Véanse P.S. WANDYCZ, Soviet-Polish Relations, 1917-1921, Cambridge, 1969; N. DAVIES, White Eagle, Red Star. The Polish-Soviet War 1919-20, and the Miracle on the Vistula', Londres, 1993. 
tantes. Para los polacos empezó la hecatombe de las dos ocupaciones, alemana y soviética, que constituían unos regímenes desconocidos hasta entonces en tierras polacas. A ambos les unía una política del terror contra las elites intelectuales y sociales de Polonia, también con el fin de eliminar a los potenciales líderes de la conspiración. La diferencia más importante consistía en el genocidio masivo y el terror universal por parte alemana y el genocidio selectivo y el terror universal por parte soviética.

Durante la guerra mundial Polonia fue un país donde existía la resistencia más extendida de todos los países ocupados, organizada en el marco del enorme Estado Subterráneo y su Ejército Nacional. Las tropas polacas actuaron también con gran esfuerzo en los frentes de la II Guerra fuera de su ocupado territorio. Disponían además de uno de los mejores servicios de inteligencia del mundo que entre otras cosas aportó a los aliados el conocimiento de descifrar "Enigma", la máquina de cifrar alemana, gracias a lo cual la mayoría de las órdenes más secretas nazis fueron conocidas por británicos y americanos ${ }^{2}$. A pesar de todo esto, durante la contienda entró en vías de realización el plan de Stalin de implantar en Polonia y en otros países de la región el régimen soviético, aprobado finalmente por los aliados occidentales en las conferencias de Teherán y Yalta ${ }^{3}$. En enero de 1944, las unidades del Ejército Rojo pasaron la frontera de la República de Polonia, empezando a instalar el poder soviético con el terror masivo, empleado esta vez no solamente por parte de los bolcheviques, sino también por los comunistas polacos, siendo muchos de sus dirigentes y miembros del partido agentes de Moscú de variado origen nacional, a menudo no polaco, que frecuentemente hablaban mal el idioma de la nación que iban a dominar

La gran diferencia entre los polacos y unos cuantos pueblos de Europa occidental que en masa hubieran deseado entonces la entrada de las tropas soviéticas, fue la experiencia directa de la sociedad polaca en los contactos con los

2. Véanse Intelligence Co-operation Between Poland and Great Britain During World War II, v. I, The Report of the Anglo-Polish Historical Committee, eds. T. STIRLING, D. NAtECZ, T. DUBICKI, co-ordinator of the English Language version of the Polish papers J. CIECHANOWSKI, Londres-Portland, 2005; Polsko-brytyjska wspótpraca wywiadowcza podczas II wojny światowej/Intelligence Co-operation Between Poland and Great Britain During World War II, v. II, Wybór dokumentów/Documents, ed. J. S. CIECHANOWSKI, Varsovia, 2005; Marian Rejewski 1905-1980. Living with the Enigma Secret, Bydgoszcz, 2005; J. S. CIECHANOWSKI, Wkład polskiego wywiadu w zwycięstwo nad Niemcami w II wojnie wiatowej / The Input of Polish Intelligence into the Victory over Germany in World War II, [Varsovia, 2010].

3. Véase más en J.[S.] CIECHANOWSKI, Movimientos migratorios polacos de carácter político durante la Segunda Guerra Mundial, "Lamusa Digital", No 6, El Exilio de Europa Central y Oriental, http://www.uclm.es/lamusa/ver_articulo.asp?articulo=138\&lengua=es.

4. Este terror no fue fruto de ninguna venganza política o ajuste de cuentas como en muchos casos, por ejemplo en España durante y después de la guerra civil. No molestaba que los comunistas presentasen los tiempos de Polonia libre (1918-1939) como un periodo del terror contra los "progresistas". 
invasores. Por una parte, en el año 1920 el marxismo soviético en Polonia era un movimiento casi inexistente, poco popular, tachado de totalitario y traidor, una opinión universal fortalecida porque la constitución de la dirección del partido estaba formada sobre todo por judíos. La guerra polaco-bolchevique dejó por una parte la constancia del terror, Ilamado en Polonia "bárbaro" y relacionado con la visión del fuerte estigma asiático presente en la mentalidad rusa, costumbre de sumisión ante las autoridades y del empleo de la violencia masiva como un elemento clave y no extraordinario de la cultura política del país vecino. Otro factor fue una mezcla de rechazo hacia el sistema soviético (expropiaciones, colectivización, tipo de educación repleta de pura propaganda, falta de libertad de expresión y confesión, etc.) y de la falta de atractivo cultural de los invasores ${ }^{5}$. A esto se añadía el conocimiento de todo tipo de represión de los años treinta y cuarenta, empezada por la persecución de los polacos en la URSS ya antes de la II Guerra Mundial. Pero la clave fue la ocupación soviética de las tierras polacas, asesinatos y deportaciones al interior de la Unión Soviética de los "enemigos de clase", en cuya definición podía caber cada polaco simplemente por serlo. En Polonia existía también el odio a lo comunista gracias a hechos simbólicos, como el asesinato en la primavera de 1940 de más de 15.000 prisioneros de guerra polacos, el conocido Crimen de Katyń, cuyas víctimas fueron los oficiales polacos del servicio activo y de reserva ${ }^{6}$. Una matanza hasta 1989 atribuida por los comunistas a los alemanes. La población polaca se daba cuenta además de que sus paisanos fueron víctimas del exterminio dentro del sistema Gulag ${ }^{7}$, siendo muchos independentistas mandados allí también a partir de 1944 y de cuyos campos pocos consiguieron volver ${ }^{8}$.

Polonia perdió su soberanía a favor de un país totalitario, de un nivel cultural y económico más bajo. Los comunistas, hacia los cuales una abrumadora mayoría de la sociedad polaca se volvió con hostilidad, fueron instalados y sostenidos en el poder gracias a factores ajenos: el Ejército Rojo y el Ejército del NKVD. Aparte de los cerca de cuatro años de la lucha contra las subterráneas

5. Aquí vale la pena mencionar la antítesis en la memoria popular polaca de la II Guerra Mundial de los brutales asesinos alemanes, conocidos sin embargo por el orden que empleaban en todos los sitios, chocando cómo numerosos criminales pudiesen tocar a Mozart u otros compositores famosos, y por otra parte los rusos y otras naciones de la URSS relacionadas en los recuerdos de los polacos con constantes violaciones, robos de relojes o casos de lavarse la cabeza en las tazas del retrete.

6. Véanse J. MACKIEWICZ, Las fosas de Katyn, Zalla, 1960; E. GIMÉNEZ CABALLERO, La matanza de Katyn (Visión sobre Rusia), Madrid, s.a.; E. A. KOMOROWSKI, J. L. GILMORE, La noche sin fin. La fosa de Katyn, Barcelona, 1974; C. VIDAL, Paracuellos-Katyn. Un ensayo sobre el genocidio de la izquierda, Madrid, 2005, págs. 225-273.

7. Dirección General de Campos de Trabajo Correctivo, Asentamientos de Trabajo y Sitios de Encarcelamiento.

8. Veánse K. SWORD, Deportation and Exile. Poles in the Soviet Union 1939-1948, Londres, 1996. 
organizaciones armadas independentistas, fue bastante fácil apoderarse de un país tan desangrado, destrozado, con la sociedad diezmada, cansada y atomizada. Todo el territorio de la Polonia reducida por las potencias estaba arrasado por la guerra, la explotación y el saqueo. Se destruyó cerca del 40\% de los bienes nacionales y el $65 \%$ de las fábricas. De algunas ciudades sólo quedaron sus ruinas (la capital, Varsovia, dejó de existir por orden de Hitler); la quinta parte de sus pueblos y aldeas fueron destruidas ${ }^{9}$. Durante la guerra perecieron o murieron de hambre, heridas y enfermedades entre 5,5 y 6 millones de ciudadanos polacos, de ellos unos 2,8 millones de judíos y polacos de origen judío y también cerca de 2,5 millones de polacos. Los daños más importantes los causó el Tercer Reich, luego la Unión Soviética. Las víctimas de las operaciones bélicas alcanzaron la cifra de entre 650 y 700 mil personas, civiles y soldados. Las pérdidas más grandes de los grupos sociales las sufrió la inteligentsia ${ }^{10}$, fuerza principal y conductora del Estado por voluntad de la nación que disfrutaba de la autoridad y el prestigio más alto. Perecieron más de la tercera parte de las personas con estudios superiores, un 35\% de la inteligentsia. La escasa elite intelectual del país que sobrevivió en Polonia fue adicionalmente debilitada por el hecho de que la emigración política polaca de los tiempos de guerra en su gran parte se convirtió en 1945 en un exilio de medio millón de personas de los tiempos de paz, incluyendo a todas las fuerzas políticas que contaban en el país. La emigración política polaca de la II Guerra Mundial tuvo de esta manera el carácter nacional, de toda la nación" ${ }^{11}$.

Un punto importante en la instalación del régimen comunista en Polonia fue el referéndum de junio de 1946, en el cual el bloque controlado por los nuevos dueños del país realmente perdió, obteniendo -según los verdaderos resultados y a pesar de una fuerte represión- el apoyo de un $27 \%$ de los votantes, mientras que la oposición, todavía no liquidada completamente, un 73\% (oficialmente, después de falsear los resultados, la relación de los votos fue de un $68 \%$ a un $32 \%$ en favor de los comunistas). Sólo en los años 1945-1948 se detuvo a unas

9. Por todo este daño no se consiguió nunca ningún tipo de reparación.

10. Es el nombre adoptado en la primera mitad del siglo XIX para definir una capa de personas educadas que se dedican de profesión a la actividad intelectual, sin que importe su procedencia social. La inteligentsia jugó y está jugando de alguna manera hasta hoy en Europa Central y Oriental un papel especial, desempeñando o pretendiendo desempeñar el liderazgo de la nación.

11. El Gobierno en el Exilio polaco funcionaba en Londres hasta los cambios de 1989, presentando en su programa reestablecer la democracia en el país. Fue un Gobierno apoyado por lo menos al principio por todas las fuerzas políticas tradicionales de derecha, centro e izquierda, a las cuales les unía el lema de la independencia de Polonia. Véanse más: J. [S.] CIECHANOWSKI, Movimientos...; K. SWORD, Identity in Flux. The Polish Community in Britain, London 1996; ídem with N. DAVIES \& J. CIECHANOWSKI, The Formation of the Polish Community in Great Britain 1939-1950, Londres, 1989. 
150.000 personas a quienes se sometía a brutales investigaciones. En los múltiples procesos se dictaron dos mil penas de muerte, no contando los miles de asesinatos clandestinos. En el viraje de 1947 y 1948, la resistencia clandestina por la independencia polaca fue abatida, existiendo desde entonces solamente pequeñas unidades sueltas. En las luchas con las organizaciones clandestinas perecieron unos 8.500 resistentes de los movimientos clandestinos y personas que les apoyaban, y también un número parecido de los funcionarios de seguridad, "Milicia Ciudadana" (la MO, policía), activistas del partido comunista y soldados de varias formaciones del régimen, Ejército Rojo incluido.

También fue llevada a cabo en Polonia una fuerte campaña de propaganda contra la oposición, con asesinatos incluidos. Las elecciones de enero de 1947 se falsificaron, con el resultado oficial de un $80 \%$ en favor de los comunistas y de un $10 \%$ en favor de la oposición, lo que fue la señal para liquidarla brutalmente aumentando la represión. Mientras tanto, se tomaban decisiones para convertir el país del mayor modo posible en un organismo de tipo soviético. Se creaban parcelas estatales, en 1946 se nacionalizó la industria y al año siguiente se comenzó a limitar el comercio privado. Por otra parte, las decisiones de conceder tierra a un millón de campesinos y la disminución del paro entre los obreros fueron bastante populares, pero estos dos planteamientos también estaban en el programa del Gobierno en el exilio y de la oposición existente en Polonia hasta 1947, aunque la segunda tarea sería difícil de realizarla rápidamente en el marco de una economía capitalista. Importante fue también una cierta atracción de algunos elementos sociales hacia el nuevo orden a causa, por ejemplo, de la avalancha de campesinos, sobre todo de las regiones más atrasadas, que se dirigían a trabajar a las ciudades industriales. En esto la autoridad comunista depositaba mucha esperanza. Su símbolo fue la construcción, cerca de la "reaccionaria" Cracovia, de una nueva ciudad: Nowa Huta [Nueva Fábrica Metalúrgica].

Cuando la autoridad de los comunistas en el bloque se fortaleció, Stalin pasó a la etapa final de sovietizar la región. Uno de los elementos de ese proceso fue la nominación en 1949 para el puesto de ministro de defensa nacional de Polonia del mariscal soviético Konstantin Rokossovsky. Al mismo tiempo, casi todos los mandos en el Ejército polaco fueron ocupados por generales soviéticos, mientras que la presencia de los todopoderosos consejeros rusos en la economía y en la seguridad se hizo muy visible. La fuerza militar del país satélite se convirtió en realidad en una parte del Ejército Rojo. Se aumentaba también la subordinación económica de Polonia a la URSS, lo que conducía a la explotación cada vez más grande del país ${ }^{12}$, junto con la obligación del uso de la atra-

12. Por ejemplo, después de 1945 de las tierras occidentales de Polonia se enviaba a la URSS fábricas enteras y equipos. Otra cuestión lo constituían los bajísimos precios de la exportación polaca a su vecino y los altos precios de los productos vendidos a Polonia por los sovié- 
sada tecnología soviética y el orgulloso rechazo del Plan Marshall por orden de Moscú, en medio de la creciente miseria.

Otra tendencia de la sovietización avanzada fue el proceso estalinista de "descubrir enemigos" tanto dentro del partido como dentro de la sociedad. Se continuaba con el terror universal y masivo, deteniendo y sometiendo bajo torturas a las personas cuyos crímenes consistían, por ejemplo, en hablar de la información procedente de la radio extranjera o contar numerosos chistes anticomunistas. Se empezó a perseguir severamente a la Iglesia católica, tradicionalmente un símbolo de resistencia cultural y nacional ante los agresores. Entre 1949 y 1955 se condenó bajo la acusación de espionaje, en la mayoría de los casos falsa, a cerca de 1.600 personas, deteniendo también a una parte de los activistas comunistas. Un papel especial lo jugaron los procesos ostentosos ante los tribunales militares, aunque la mayoría de las sentencias se declaraba en juicios secretos. Los polacos ya sabían que el totalitarismo soviético iba a ser más radical que el totalitarismo alemán, ya que este último se dejaba llevar por la vieja costumbre burguesa de no hacer daño a sus partidarios. Por ejemplo, si uno era fiel al partido nacional socialista de Hitler, si apoyaba su programa y cumplía sus deberes políticos, esta persona podía estar segura de su situación personal, incluso los colaboracionistas en los países ocupados gozaban de protección. El rasgo inminente del comunismo era, sin embargo, la constante búsqueda del enemigo interno. El genial invento de los bolcheviques consistía en la creación del terror preventivo, que, en la situación descrita por Stalin donde la "lucha de las clases se agrava al mismo tiempo que los progresos en la construcción del socialismo", necesitaba constantemente a este enemigo que actuaba dentro del sistema, sin el cual la dictadura comunista se convertiría en un típico modelo de ocupación occidental -un juego entre los ocupados y los ocupantes con el fin de resolver quién y cuándo iba a ganar-. Se empleaba el terror preventivo, donde todos estaban bajo sospecha, desde un mendigo (oficialmente inexistente) hasta prácticamente el primer secretario del partido. Así en la sociedad disminuyó el eje entre el ocupado y el ocupante, ya que pertenecer a esta primera categoría no daba ninguna garantía. Ese sistema fue empleado por primera vez en la nueva sociedad rusa, donde se destruyó antes o después prácticamente todo lo que quedaba de la Rusia de los zares, un imperio ni feudal ni capitalista, una brutal dictadura autoritaria de rasgos asiáticos ${ }^{13}$. El mismo terror se intentaba introducir en otros países que cayeron bajo el domi-

ticos. Mientras, prácticamente hasta el final del comunismo, en la propaganda dirigida sobre todo a los extremistas de izquierda del Occidente, Moscú presentaba una visión del casi mantenimiento de Polonia por la URSS.

13. Véase J. S. CIECHANOWSKI, Los campos de concentración en Europa. Algunas consideraciones sobre su definición, tipología y estudios comparados, "Ayer", 1 (57), Madrid, 2005, pág. 61. 
nio soviético, Polonia incluida. Así se llegó al símbolo de la sovietización: la nueva constitución de 1952, corregida personalmente por Stalin, y que introducía el nuevo nombre del Estado: la República Popular Polaca.

\section{Año 1956: fin de la etapa estalinista de la dictadura comunista}

El fundamento de los sucesos del año 1956 estaba basado en el proceso de desestalinizacion empezado lentamente después de la muerte de Stalin tres años antes, aunque precisamente en Polonia la represión alcanzó en algunos aspectos su apogeo tras la desaparición del dictador comunista. A esta etapa de liberalización gradual del totalitarismo se la Ilamó "el deshielo". En diciembre de 1953 huyó al Oeste el vicedirector del X Departamento (responsable de la persecución de los enemigos dentro del partido) del Ministerio de Seguridad Pública (MBP) Józef Światło. Su detallada relación en la Radio de Europa Libre reveló al mundo el carácter brutal del sistema y su modelo procedente directamente de NKVD. Los cambios en Polonia empezaron, pues, en 1954, aun cuando la dictadura se mantenía en su estado puro de dureza, en un momento en que se producía, además, el empeoramiento de la situación económica. El plan del partido era controlar y limitar los cambios, para que realmente sólo disminuyera el nivel de represión y control aparente. Bajó el número de detenciones, se limitó la severa censura y se permitía una cierta crítica en la prensa de la actividad de las autoridades. En diciembre de 1954 se liquidó el MBP, el odiado símbolo de la "nueva" Polonia, lo que era el lugar de trabajo -como otros órganos de represión- de muchos antiguos miembros de las Brigadas Internacionales que participaron en la Guerra Civil Española. Gradualmente disminuyó la dinámica de las inversiones en la industria pesada, los enormes gastos para el armamento y la colectivización de la agricultura. En todo el país se creaban los clubes de discusiones, sobre todo de la inteligentsia joven, también relacionada con el poder.

El momento crucial fue la crítica y condena, todavía secreta, por parte de la nueva dirección de la URSS del culto a Stalin y su época, ocurrida en febrero de 1956 en Moscú durante el XX Congreso del Partido Comunista de la Unión Soviética. La tensión internacional estaba disminuyendo. En marzo falleció en la capital soviética, en unas circunstancias misteriosas, el líder de la Polonia estalinista Bolesław Bierut, substituido en el puesto de primer secretario del CC del Partido por el dogmático, pero más moderado obrero, Edward Ochab. Mientras tanto en el país aumentaba la crisis social y política, produciéndose un fermento extendido también a las capas más altas del partido. A finales de abril de 1956, el Parlamento (Sejm) votó la amnistía. La gente se dio cuenta que el todopoderoso partido estaba muy debilitado.

En la crítica, expresada de una manera muy cuidadosa en varios ámbitos, se demandaba: transparencia en las actuaciones de las autoridades, liberación de los presos políticos, rehabilitación de los falsamente acusados, castigo legal a 
los culpables de usar métodos criminales de investigación, cambio de valoración del Ejército Nacional y abandono de la persecución y discriminación de sus antiguos soldados, rechazo de la doctrina del realismo socialista en la cultura, eliminación de los privilegios de la autoridad (sobre todo de las tiendas y servicios especiales "por detrás de las cortinas amarillas"), cambios en la administración de la economía o eliminación del ruso de las escuelas. Entre abril y mayo de 1956, gracias a la amnistía, salieron de las cárceles cerca de 35.000 personas, entre ellas 7.000 presos políticos. A algunos de ellos se les rehabilitó, sobre todo a los comunistas condenados.

En los meses siguientes, la crisis se agravó con el aumento de las demandas de cambios y el aumento del caos entre los comunistas. En esta situación el jueves 28 de junio de 1956 estalló en Poznań una revuelta popular que fue el punto clave de los acontecimientos polacos del año, constituyendo el principio de la lucha por parte de los obreros polacos por la libertad del país. Fue una huelga general, seguida por una pacífica y masiva manifestación callejera que se convirtió en una insurrección popular, sofocada por las fuerzas armadas comunistas (Ejército, Cuerpo de Seguridad Interna (KBW) y la MO). Ocurrió en la capital de la región tradicionalmente más rica de Polonia, la Gran Polonia (Wielkopolska ${ }^{14}$ ) que después de la guerra gozaba ya solo de un potencial relativo en un país destruido por las ocupaciones y la economía comunista. La región fue considerada por las autoridades como muy sospechosa, especialmente por la fuerte tradición de patriotismo, siempre en confrontación contra el numeroso elemento alemán. Con el poquísimo apoyo hacia los comunistas, estos últimos destruían el sistema agrario de Wielkopolska persiguiendo brutalmente a los "kulaks", agricultores grandes y medianos (pero en el sentido polaco de entonces, donde un agricultor grande no significaba un terrateniente, pero sí un dueño de 50 y 100 hectáreas, con la reforma agrícola realizada antes de la guerra) que dominaban en aquellas tierras. Eso provocaba obviamente la bajada drástica del rendimiento de la agricultura y problemas graves en el mercado de alimentos. Además, las normas productivas impuestas a Wielkopolska fueron muy elevadas, siendo la región peor dotada del presupuesto estatal. El plan para 6 años con sus errores, imprescindibles desde el punto de la ideología, dio como resultado que se intentaba economizar también bajando los sueldos de los obreros y fijando los niveles de normas cada vez más altas.

La situación en las ciudades también era difícil, aunque no más que en otras regiones. En la primavera de 1956 el ambiente en las fábricas de Poznań ya era muy tenso. A los obreros, un proletariado bien asentado y con mucha tradición ${ }^{15}$, se les pagaba peor que antes de la guerra. Resulta curioso que sus sueldos fueran

14. A diferencia de la Pequeña Polonia con la capital en Cracovia.

15. A diferencia de nuevos centros creados después de la guerra, como Nowa Huta, Wrocław, Szczecin o Varsovia. 
mucho más bajos que durante la ocupación alemana (Wielkopolska fue incorporada directamente al Reich), los nazis pagaban relativamente bien a los obreros de las industrias pesadas, teniendo en cuenta la necesidad de obtener un gran rendimiento de su trabajo. En este clima en toda Polonia los trabajadores amenazaban a los representantes de las autoridades con ir a la huelga. Una parte de la organización del partido en la fábrica metalúrgica Cegielski (entonces Stalin) apoyaba generalmente las demandas de los obreros, lo que estaba ya muy lejos de la ortodoxia y daba constancia del caos en todo el país, porque ocurría también en otros lugares del trabajo. La visita del ministro de industria maquinaria el 27 de junio no contentó a los obreros, quienes dieron por hecho que las autoridades se retiraban de los acuerdos sociales antes aprobados.

La huelga empezó por la madrugada, cuando los obreros de Cegielski salieron a la calle. El primer signo de que las exigencias económicas dentro de unas horas se convertirían en políticas consistía en que los trabajadores quitaron el rótulo con el nombre del odiado dictador soviético ${ }^{16}$. Por el camino al centro de la ciudad se incorporaron a la manifestación también los obreros de otras fábricas -ya en contacto desde hace tiempo con los de Cegielski-y personas de todas las capas sociales, tales como tranviarios de ambos sexos, costureras, funcionarios, miembros de la inteligentsia e incluso niños. Los manifestantes pasaron cerca de la entrada de los Mercados Internacionales de Poznań. Durante el recorrido se dirigieron a la sede del Consejo Nacional de la Ciudad (una especie de Ayuntamiento comunista) en la plaza de Stalin (antes y ahora del vate nacional Adam Mickiewicz). Allí una manifestación de unas 10.000 personas se convirtió en la de unas 100.000. La gente presentaba lemas sociales y políticos pidiendo "Pan" y “Libertad". Se gritaba: “¡Fuera los bolcheviques!”, “¡Fuera el bolchevismo!", „Fuera con semejante libertad!", “¡Fuera los comunistas!”, "¡Fuera la burguesía roja!”, "¡Demandamos elecciones libres bajo el control de la ONU!", "¡Que viva Mikołajczyk!” [líder del partido agrario, en 1947 forzado a escapar de Polonia después de las elecciones falseadas], “¡Demandamos religión en las escuelas!”, „¡Fuera Rokossovsky!”, “¡Sin engaños y mentiras!”. También estuvo presente la simbólica nacional, escandiéndose "¡Fuera los rusos!", “¡Fuera los moscovitas!”, „¡17 años de esclavitud!”, „¡Fuera ruskie!” y “¡Fuera kacapy!" [palabras polacas peyorativas para nombrar a los rusos]. Los manifestantes cantaban el himno "Jeszcze Polska nie zginęła" ["Todavía Polonia no ha perecido"], la Rota, una canción nacional polaca, símbolo de la resistencia contra los alemanes, esta vez con el texto cambiado el cual decía "hasta que se convierta en polvo y cenizas el alboroto soviético" [en vez de "teutón"]. Se cantaban además canciones religiosas. Una parte importante de la simbólica de la protesta se reflejó también en las pancartas: “¿Queremos libertad!”, “¿Queremos elec-

16. En realidad, gracias a los rasgos característicos de la economía comunista, simplemente presentar los postulados económicos significaba una fuerte actuación política y antisistema. 
ciones libres!", “iMuerte a los traidores!”, “¿Queremos a Dios!”, “¡Demandamos Polonia libre!", “¡Fuera con la democracia rusa!” [con el uso de la palabra peyorativa "ruska"]. En un tranvía inmovilizado se escribió “¡Fuera la dictadura!”.

Los manifestantes entraron a los edificios públicos, como el Comité de la Región del Partido (la clásica figura revolucionaria del pueblo tomando el palacio de la autoridad), que demolieron en parte, destruyendo sobre todo los símbolos de la autoridad comunista y poniendo en los edificios las banderas polacas, blanco-rojas, en vez de las odiadas rojas, comunistas. Destruyeron los aparatos que causaban interferencias a las emisiones de radios polacas anticomunistas en el extranjero. Actuaban con el sentido de autoorganización típica de los habitantes de Wielkopolska. Los insurrectos entraron también en la sede de la milicia, donde los funcionarios de la MO les entregaron las armas. La falta de reacción de ésta les llevaba entre otros a la convicción y a la extensión de los rumores de que la rebelión se extendía a todo el país, a otras grandes ciudades. Mientras tanto, las autoridades comunistas de Poznań pidieron a la central una intervención militar. La decisión de sofocar la revuelta por la fuerza la tomó el Buró Político del Comité Central (CC) del Partido Obrero Unificado Polaco (POUP), que encomendó al viceministro de defensa nacional, el general soviético Stanisław Popławski (realmente Sergey Gorojov), un ruso, la organización de la comandancia. El jefe del Estado Mayor, el general Jerzy Bordziłowski, otro ruso, dio orden a la Escuela de Oficiales de los Ejércitos Blindados y Mecanizados en Poznań "de usar armas contra los provocadores", aunque al principio las fuerzas gubernamentales tuvieron prohibido hacerlo. Mientras debatía el Buró Político, entre la multitud se corrió el rumor de la detención de la delegación obrera que dos días antes negociaba en Varsovia. No era verdad, pero los manifestantes se movieron espontáneamente: una parte liberó a los presos políticos de la cárcel y otra empezó el asedio del edificio de la odiada Dirección de Seguridad Pública (UB) de la Región, símbolo del terror comunista y la sumisión de la dictadura totalitaria a Moscú. Se empezó por tirar piedras. La manifestación pacífica se convirtió en una lucha callejera feroz cuando se produjeron los primeros disparos desde la sede de la UB y los primeros muertos. Aparecieron, no por primera y última vez en las revueltas obreras polacas contra los comunistas, rumores de que desde el edificio de la UB disparaban los rusos disfrazados con uniformes polacos ${ }^{17}$. La multitud gritaba “¡Fuera con los fascistas!”, “¡SS!” y “¡Bandidos!”18. Los manifestantes se dispersaron corriendo, atacando desde entonces el edificio en grupos pequeños con cócteles Molotov. Llegaron también los civiles abastecidos ya de armas adquiridas en la cárcel, en las comisarías de milicia y en los estudios militares de las escuelas superiores, comenzando el tiroteo regular. Los primeros tanques mandados de la Escuela Militar para proteger al edificio de la UB no cumplieron las órdenes, no

17. Lo mismo se decía del Ejército mandado a Poznań que entró a la ciudad por la tarde.

18. En los años ochenta el lema más popular entre los protestantes fue "MO-Gestapo". 
disponiendo además de munición pesada. Los manifestantes se apoderaron de varios tanques o los quemaron. Las mujeres gritaban a los jóvenes soldados: "¿¡A las madres vais a disparar?!". Algunos de ellos se dejaban desarmar, a menudo confraternizando con los manifestantes. Otros grupos de soldados, no tan preparados para solidarizarse con la multitud, se retiraron, siendo algunos pegados por los grupos de protesta. Unos cuantos se adhirieron al tiroteo contra la seguridad creando la esperanza que el Ejército no iba a usar armas contra los civiles.

Por los sucesos al lado de la sede de la UB la revolución descubría su carácter nacional y anticomunista. Los manifestantes entraron al terreno de los Mercados Internacionales con una bandera polaca ensangrentada. Tuvo lugar por lo menos un linchamiento a un funcionario de seguridad que murió en el hospital, cuando los manifestantes, después de pegarle hasta la pérdida de conciencia, no querían dejar durante algún tiempo que se lo llevase la ambulancia, algo que se parecía a los numerosos linchamientos de los miembros de la AVH húngara unos meses después. Por la tarde fue asesinado a tiros por los comunistas en la retaguardia de los garajes de la seguridad el símbolo del levantamiento, Roman Strzałkowski, un niño de 13 años $^{19}$. Otro chico, bajo la lluvia de balas, interceptó de una tranviaria herida la bandera blanco-roja, cayendo muerto. No se sabe hasta hoy quién era. A otro joven polaco de 16 años que se defendía con el arma le asesinaron los funcionarios de la UB disparándole con el cañón apuntando a su frente.

La lucha en la ciudad se agravaba. Se construían barricadas con los tranvías derribados. Se intentó sin éxito llevar el levantamiento fuera de Poznań. Las autoridades mandaron al final para pacificar la ciudad cuatro divisiones del Ejército de más de 10.000 soldados con 420 tanques, cañones y carros blindados, fuerzas suficientes para una batalla por una ciudad grande y fortificada. Todo eso contra los insurrectos que disponían de entre 186 y 188 ejemplares de armas, unas granadas de mano y botellas con gasolina. Los oficiales políticos de las divisiones, herencia de la institución del comisario político, contaban a los soldados que esta rebelión contrarrevolucionaria fue provocada por los saboteadores occidentales que vinieron a los Mercados y que querían incorporar Polonia a Alemania. Dos tanques de los primeros que llegaron a la ciudad se perdieron, los poznanienses los tomaron y disparaban contra otros carros. Pero otros de estos nuevos tanques se movían de una manera decidida desprendiendo gases. La gente lanzaba contra ellos las botellas con gasolina. El Ejército se apoderó de la zona del edificio de seguridad, pero sin conseguir la pacificación de la situación. El general Popławski, que vino en avión desde Varsovia, preparaba el bombardeo de los insurrectos desde el aire en caso de necesidad. A

19. Junto con Peter Mansfeld, un joven húngaro ahorcado con la edad de 18 años por conspiración cuando tenía un año menos, se convirtieron en las víctimas emblemáticos de las anticomunistas revueltas populares de 1956. 
pesar del terror de la Información Militar, algunos oficiales consiguieron pruebas de que el Ejército soviético se estaba moviendo hacia la frontera polaca, dejando constancia de que se estaba preparando una intervención militar soviética. Los ataques esporádicos duraron toda la noche a pesar del toque de queda. Se disparaba a la gente también desde los tanques. Empezaron las detenciones, con el tratamiento de los presos ya muy bien conocido. El 29 de junio por la mañana la ciudad estaba pacificada. Se conoce los nombres de 58 muertos que cayeron entre el 28 y 29 de junio, otras fuentes hablan de 74 o hasta 113 cadáveres hallados después de la revuelta. Entre los muertos documentados había 50 civiles, 4 soldados, 3 funcionarios de la UB y un miliciano. Se ejecutó probablemente a más de una decena de soldados que se opusieron a cumplir órdenes y disparar contra el pueblo. Unos cientos de personas fueron heridas y 746 detenidas, en su mayoría obreros.

Durante el día 29 se organizó otra manifestación de unos cuantos miles que se retiraron al ver los tanques. Ese mismo día también tuvieron lugar casos sueltos de tiroteo. Por la noche, en un discurso trasmitido por la radio, el primer ministro Józef Cyrankiewicz anunció la represión contra los participantes en los sucesos, hablando de la "criminal provocación" de los agentes "imperialistas" que se aprovecharon de las dificultades y el descontento en algunos lugares de trabajo. Usando la retórica estalinista amenazaba, declarando expresamente en que consistía la dictadura: "Cada provocador o loco que se atreva a levantar la mano contra la autoridad popular, que esté seguro que la autoridad popular le cortará esa mano".

A pesar del bloqueo de la ciudad y las mentiras propagandísticas presentadas por las autoridades, los hechos de Poznań conmovieron a la sociedad, agravaron las luchas internas en el partido creando el pánico entre los comunistas porque los que se opusieron a la autoridad constituían teóricamente la vanguardia de la revolución (aunque se intentó decir que fueron los "reaccionarios"). Provocaron también protestas más allá de las fronteras de Polonia, sobre todo por los cientos de testigos del levantamiento entre los participantes extranjeros de los famosos Mercados Internacionales de Poznań. Eso logró que la revuelta se hiciera muy popular en el Oeste entre los círculos democráticos. Por ejemplo, en Paris se organizó un mitin en el cual intervino en defensa de los obreros de Poznań Albert Camus. Refiriéndose a la declaración de Cyrankiewicz afirmaba que si las autoridades comunistas iban a "defender" al pueblo de la misma manera, "dentro de poco en Polonia van a gobernar sólo gente con una mano". Un papel enorme lo jugó la Sección Polaca de la Radio de Europa Libre informando a sus paisanos de lo que realmente pasaba, transmitiendo apoyo del Occidente, aunque con el miedo de no ser la fuente de instigación a la insurrección y al mismo tiempo del hundimiento de las protestas en un mar de sangre. Una presión increíblemente irresponsable venía de los elementos oficiales de los Estados Unidos para que la Radio incitase a los obreros de Poznań a la lucha. Su director, Jan Nowak-Jeziorański no cedió, a diferencia de los jefes 
de la sección húngara que en octubre excitaban a la insurrección, prometiendo una ayuda del Occidente que nunca llegó ${ }^{20}$.

Después de la pacificación empezaron los preparativos de los procesos políticos bajo la acusación de intentar cambiar el sistema político a mano armada. A pesar de los cambios y el fermento dentro del sistema comunista, las autoridades querían acusar a 75 personas de entre todos los detenidos. Al final se culpó oficialmente a 22 insurrectos, quienes fueron sometidos a juicios ostentosos que pretendían demostrar que los "sucesos" fueron encabezados por unos gamberros, aunque la tesis oficial de los fiscales consistía en que los acontecimientos fueron resultado de la "provocación de los servicios de inteligencia americanos y los de Alemania occidental y el subterráneo reaccionario". Gracias a los cambios de Octubre en la cárcel cumplieron condena sólo 3 personas juzgadas por la muerte del funcionario de la UB, pero muchos de los detenidos fueron condenados de otra manera, haciendo uso del mecanismo de la "represión" silenciosa, posible solamente en un marco de la economía "socialista", donde el Estado controla casi todo y donde no es posible conseguir trabajo deseable o realmente ningún trabajo sin la aceptación de las autorida$\operatorname{des}^{21}$. Los comunistas nunca perdonaron tampoco al abogado Stanisław Hejmowski, el más valiente de los defensores de los acusados, quien, sin mirar las consecuencias, se atrevía a declarar ante el tribunal que la gente se dispersó en busca de armas cuando cayeron los primeros disparos del edificio de seguridad. Aún después del Octubre polaco se le perseguía con altos impuestos arbitrarios, citando a sus clientes a interrogatorios, etc. Acosado, Hejmowski murió prematuramente en 1969.

El cambio en la dictadura en el año 1956 no estaba sin embargo asegurado. Poznań produjo entre las autoridades la impresión de que por una parte había que liberalizar el sistema, pero por otra estrechar filas, porque la aversión de la mayoría de la sociedad les podía costar caro a pesar de la cautela soviética ${ }^{22}$.

20. Con la visita de George Bush a Hungría en junio de 2006 se levantó de nuevo la polémica del porqué los Estados Unidos no ayudaron militarmente a Hungría. De la misma manera no hubieran ayudado a Polonia, si ésta se hubiese levantado tan abiertamente. El temor de la bomba nuclear fue reservado solo a arriesgarse en la situación que tocaba directamente a los intereses americanos y no en la zona de influencia dejada a los soviéticos por los mismos yanquis poco más de una década antes. La administración de Eisenhower prometía quitar a los soviéticos de Europa, aunque no tenía ni medios ni planes para hacerlo. Desde esta perspectiva fue completamente irresponsable apelar a los húngaros por la Radio de Europa Libre a que expresasen su actitud antisoviética, dando hasta las recetas de cóctel Molotov.

21. Este tipo de consecuencias para los cientos de habitantes de Poznań era recordado este año durante las celebraciones del aniversario. Como ejemplo el de una tranviaria que fue forzada, gracias a su participación en la revuelta, a vivir 32 años con su marido e hijo en 17 metros cuadrados.

22. El levantamiento de Poznań produjo también su eco en otros países comunistas, terminando con una resonancia social en Estados cercanos, como Hungría o Checoslovaquia, o con 
Durante el VII Pleno del CC del POUP (18-28 de julio) muchos dirigentes comunistas, como Ochab, parecían no entender que era posible que los obreros saliesen a la calle contra la autoridad "popular". Una parte percibía que no había ningún complot imperialista y buscaba a cualquier precio posibilidades de ofrecer algo para que las masas se tranquilizasen. Nacía entonces la leyenda de la importancia del ala liberal en un partido que se jugaba su poder dependiendo además de la imprevisible dirección de la lucha por el poder en Moscú. Nadie estaba seguro de a qué tendencia del partido polaco iban a apoyar los camaradas soviéticos y lo que realmente significaba el informe de Nikita Jrushchov, cuya posición tenía que sorprender, especialmente porque fue conocido su papel en el genocidio en Ucrania, también contra los polacos. El informe debilitaba mucho al partido, quitando a un país totalitario un elemento clave, la ideología actual como el único instrumento de legitimidad. El fermento y la disminución del prestigio comunista hasta entre sus propios miembros aumentaron al constituir Polonia el único país donde este documento soviético se hizo bastante accesible gracias a una edición limitada para los miembros del partido.

Paradójicamente, Poznań fue visto como una señal de la debilidad del partido. Desde julio de 1956 crecían las demandas del pago de atrasos y subida de salarios, se creaban autogestiones obreras en las empresas industriales y se liquidaban las cooperativas productivas de tipo comunista en el campo. Mientras tanto el partido parecía no poseer liderazgo. El candidato para primer secretario parecía muy aceptable para ambas alas del partido. Se trataba de Władysław Gomułka, líder de Polonia comunista en los tiempos de la implantación del sistema (entre 1945 y 1948 la represión fue más grande que en tiempos posteriores), responsable del terror, pero apartado del poder, considerado como una especie de "liberal" y símbolo del posible camino polaco al socialismo ${ }^{23}$. Fue aceptado por los duros del partido y por los menos radicales, término dentro de aquella dictadura más aceptable que el de "más moderados". Los comunistas entendían que el mecanismo de mantenerse en el poder consistía en canalizar las protestas de las masas dentro de las lógicas del partido. El POUP fue la fuerza que se puso a organizar mítines, a invitar a la gente de la calle a estas manifestaciones intentando convencer de la inevitabilidad de los cambios.

Así llegó el Octubre de 1956, un movimiento masivo de liberalización y fermento social, agravando la situación de una manera aparente. Pasó por el país una oleada de protestas antisoviéticas, pro-nacionales y pro-religiosas. Como no se podía ir directamente contra el partido y la dictadura, se atentaba contra

una reflexión sobre el peligro del debilitamiento del partido entre los dirigentes comunistas en otros países. Véase Węgrzy uratowali nam skórę [Los húngaros nos salvaron el pellejo], entrevista con el Prof. Andrzej Paczkowski, "Poczta Polska", 28 de junio de 2006.

23. Este "camino polaco" fue resultado de las declaraciones de Jrushchov que admitían ese tipo de falta a la ortodoxia, a pesar del ejemplo peligroso de la Yugoslavia de Tito. 
lo que más dolía a los comunistas, pero aparentemente no constituía un intento de derribar el régimen. Así se pedían respuestas claras de lo que la población quería escuchar oficialmente de boca de la autoridad, conociendo muy bien las respuestas, ¿quién era responsable de Katyń?, ¿cómo explicaban los comunistas el Levantamiento de Varsovia de 1944?, ¿cómo se veía la invasión de las tropas soviéticas acordada con los aliados nazis alemanes y realizada en septiembre de 1939? Nadie en los mítines en las fábricas podía pedir abiertamente el fin del comunismo en Polonia. Para decir lo mismo, se comparaba Stalin con Hitler, también la política de exterminio de ambos totalitarismos, pidiendo el fin de la ocupación soviética, el regreso del Gobierno de Londres a Polonia después de unas elecciones libres e incluso la devolución de Leópolis y Vilnius. A veces se pedía hasta la democracia, como si fuera posible dentro del sistema. Las autoridades interceptaban las cartas de los obreros que decían "El comunismo es el mayor explotador de los trabajadores"; tuvieron que limpiar paredes o recoger folletos llenos de inscripciones en donde se expresaba que, por ejemplo, el capitalista antes de la guerra pagaba realmente tres veces más que el comunis$\operatorname{ta}^{24}$ y más radicales como que había que "serrar" a la "plutocracia roja".

Los dirigentes del partido, para no perder el control en esta situación inestable, decidieron realizar cambios en los puestos más altos del partido sin consultar a Moscú. Bajo una fuerte presión social, es decir los mítines en las fábricas y universidades, donde nadie aceptaba la visión de Jrushchov (división entre los "crímenes de Stalin" y el "camino bueno" del comunismo), se convocó al pleno del Comité Central del partido. El 19 de octubre, al comienzo de la reunión, las unidades del Ejército Rojo estacionadas en Polonia ${ }^{25}$ empezaron la marcha hacia Varsovia. El mismo día inesperadamente llegó en avión a Varsovia la delegación del CC del PSUC encabezada por Jrushchov. Sabiendo que los tanques soviéticos se dirigían en camino a la capital polaca, Ochab declaró que no iba a hablar con los dirigentes soviéticos bajo la presión militar y quería hasta dirigirse a la nación por radio. Fue paradójico que este dogmático comunista, prácticamente en contra de Jrushchov, aseguró la presencia de Gomułka en las conversaciones polaco-soviéticas del 19 y 20 de octubre. Este último convenció al líder ruso que no iba a cambiar los fundamentos del sistema, ayudando así a alejar la amenaza de la invasión soviética ${ }^{26}$ y posibilitando su

24. Se indicaba también que en los países capitalistas, como en Polonia de antes de la guerra, había derecho de huelga.

25. Es decir, Grupo Norte de los Ejércitos Soviéticos. Las unidades soviéticas y después rusas permanecieron en Polonia hasta 1994.

26. En su mayoría, los historiadores polacos opinan que los húngaros salvaron a Polonia de la intervención militar soviética, siendo el estallido de la insurrección de la nación hermana la causa de la detención de las actividades soviéticas que hacían la posible invasión cada vez más aparente. La URSS se opuso fuertemente a la demanda de retirar de Polonia a Rokossovsky y como resultado de un debate en Moscú entre los dirigentes comunistas con la participación de 
elección como primer secretario del partido, adquiriendo el apoyo de muchos ámbitos, por ejemplo en un gran mitin del 24 de octubre. Fue prácticamente forzado a declarar en una situación de entusiasmo masivo por la caída del estalinismo y de la esperanza de poder seguir con las reformas y el deshielo: "La clase obrera dio a la directiva del partido y al gobierno una lección dolorosa. Los obreros de Poznań, utilizando el arma de la huelga y saliendo a manifestarse a la calle el «jueves negro» de junio, gritaron con una gran voz «¡Basta ya! ¡Así no se puede seguir! ¡Volved atrás del camino falso!»”. Eso se reconoció por primera y última vez durante el dominio del comunismo polaco. Fue una declaración ante una multitud varsoviana que pedía cambios. Realmente no se sabe si el líder comunista, Ilamado antes el "pequeño Stalin", apartado del poder por otros estalinistas, se daba cuenta de su herejía. Probablemente sí.

Gomułka nunca se convirtió en héroe nacional, porque al fin y al cabo fue un comunista ortodoxo, para muchos poco atractivo por su simpleza intelectual y doctrinarismo. Pero supo aprovecharse bien de su imagen como un mal menor o hasta un posible Imre Nagy polaco, una posibilidad que pronto resultó un malentendido. Gomułka fue más un héroe momentáneo del partido usado como una especie de amortiguador, creado en sus mítines, cuando los comunistas hacían todo lo posible para presentarse como demócratas casi natos, rechazando la violencia masiva de los años anteriores como si fuera obra de un grupo muy reducido de personas de procedencia enigmática o indicando directamente la responsabilidad por los "errores y desviaciones" a la URSS y en voz alta, a la seguridad y Bierut, sin ver, sin embargo, la necesidad de perseguir los crímenes y a los criminales ${ }^{27}$. Gomułka presentaba también otro valor. Se convirtió en el símbolo para una parte de la elite que, aunque no creía en los lemas comunistas, se sentía en la obligación de llegar al acuerdo con el poder sobre todo para su bien personal, para poder disfrutar de privilegios sin ser tachados de traidores y colaboracionistas. "Liberalizar" al nuevo primer secretario significaba para ellos disculparse de la cooperación con las autoridades.

Catorce años después fue el mismo Gomułka quien mandó disparar cerca de los astilleros de la costa, no contra la multitud que asediaba los odiados edificios comunistas, sino contra los obreros que se dirigían a trabajar en los astilleros. Un resto del terror masivo estalinista, empleado hace años, que no iba dirigido solamente contra los enemigos. Esta decisión le costó al primer secre-

chinos, búlgaros, alemanes orientales y checoslovacos, la presión aumentó. Los días 22 y 23 de octubre de nuevo había peligro de intervención soviética. Empezó sin embargo la revolución húngara. También fue importante la oposición de los comunistas chinos a la intervención en Polonia.

27. Algunos relacionaban este mecanismo con la aparición de la leyenda de los crímenes alemanes cometidos simplemente por los nazis y no por un gran número de alemanes, nazis incluidos, con el tácito o alto apoyo por parte de la gran mayoría de la nación. 
tario, ya bastante apartado de la realidad, el liderazgo. Le sustituyó un barón del partido de la región minera de Silesia, Edward Gierek, tachado de liberal, que sin embargo estuvo presente en Poznań en 1956 como delegado del partido y que debió participar en las decisiones gracias a las cuales el número de víctimas resultó tan elevado. Por si esto fuera poco, durante los funerales estatales, unos días después de la revuelta, él mismo elogiaba a los "heroicos defensores de la legalidad popular".

Octubre de 1956 cambió poco y mucho a la vez. Mucho, porque realmente se terminó la etapa estalinista en Polonia, aunque la dictadura permanecía dura. Poco, porque todos se daban cuenta del alejamiento oportuno de la intervención soviética y de la tragedia de Hungría ${ }^{28}$ que constituía la advertencia de lo que podía pasar en Polonia, y que empezando la manifestación en favor de su libertad el 23 de octubre, solidarizándose en Budapest ante el monumento del héroe de las dos naciones, el general Józef Bem con el pueblo polaco (el lema "Poznań-Varsovia-Budapest"), terminó con una invasión soviética que sofocó en sangre las aspiraciones independentistas y democráticas del pueblo húngaro. A los polacos, a quienes los rusos siempre temían más que a otras naciones, estando acostumbrados a sus rebeliones, se les dejó en paz. Los soviéticos se dieron cuenta de que sus tradicionales adversarios, esta vez muy debilitados, buscaban el compromiso, mientras que los húngaros presentaban una actitud normalmente típica para los polacos, provocando el levantamiento ${ }^{29}$.

Hasta finales de 1956 ocurrieron hechos que realmente significaban cierta liberalización. Se eliminó el terror general. Se reconoció la independencia de la Iglesia, siendo liberado el Primado de Polonia, cardenal Stefan Wyszyński, detenido desde 1953. Las autoridades comunistas y la Iglesia sellaron un acuerdo fijando el mecanismo de los nombramientos de los puestos eclesiásticos y devolviendo la religión a las escuelas. Se cambió la cúpula del Ejército, el mariscal Rokossovsky y los generales soviéticos se marcharon a la URSS, ninguno de ellos -como tampoco los consejeros de seguridad- respondió por sus crímenes. Durante la visita de la delegación polaca a Moscú se fijaron las reglas del estacionamiento de las tropas soviéticas en el país satélite. Se reanudaron también los desplazamientos de los polacos de la URSS a Polonia. Se rehabilitó a muchos condenados en los procesos políticos. La actitud hacia los artistas se hizo menos dura, produciéndose cambios en las autoridades de las organizaciones sociales hasta entonces completamente controladas por los comunistas, por ejemplo la Asociación de los Literatos Polacos, o la Asociación de los Periodistas Polacos. Los ámbitos católicos empezaron a organizar Clubes de Inteligentsia Católica. Se liquidó la Asociación de la Juventud Polaca, instru-

28. Los dos únicos países donde los comunistas no consiguieron controlar los cambios postestalinistas.

29. Véase Węgrzy uratowali nam skórę... 
mento de la dictadura para adoctrinar a los jóvenes sobre todo de origen campesino y obrero, pero inmediatamente se crearon otras organizaciones de tipo parecido, aunque ya no tan radicales. Se permitió crear en las empresas estatales unos consejos obreros. Se mejoró parcialmente la administración de la economía, intentando al igual que en algunos otros países comunistas "capitalizar el socialismo", es decir volver a algunos aspectos del mercado capitalista, aunque los mecanismos nuevamente empleados no fueron eficaces. Se paró espontáneamente la colectivización, desintegrándose en el campo el 80\% de las cooperativas productivas ${ }^{30}$. Sin embargo, los elementos claves del sistema permanecieron: dominación del partido comunista centralizado y jerárquico, monopolio informativo, carácter policíaco del Estado, primacía de la propiedad estatal sobre la privada y sobre todo pertenencia al bloque soviético bajo el dominio absoluto de Moscú.

Además, ya desde octubre, Gomułka intentaba dominar el movimiento social espontáneo que consideraba peligroso para el régimen. Realizaba su viejo lema expresado poco después del término de la guerra: "Una vez adquirido el poder, no lo vamos a devolver jamás". Seguía como fiel aliado de Moscú, sabiendo que nadie más garantizaba el poder de los comunistas en Polonia. Consideraba que la revolución obtuvo su fin deseado, es decir le llevó al poder. Desde entonces él sabía mejor qué era apropiado y qué no. Ni se le ocurrió perseguir los crímenes estalinistas o los responsables de las víctimas de Poznań, porque eso debilitaría al partido. La esfera del miedo y de la sumisión ideológica, consecuencias sociales del terror y de la propaganda, dos pilares de los gobiernos totalitarios, según Hannah Arendt, disminuyeron, pero no fueron eliminados, gracias a lo cual no sabemos realmente cuántos polacos decidieron no demostrar sus sentimientos en Octubre. Los comunistas se aprovecharon hasta el final de este miedo y otros frutos mentales causados durante el estalinismo.

Ya a finales de 1956 el proceso de la liberalización estaba detenido y la revolución "canalizada" ${ }^{31}$. En enero del año siguiente, Gomułka organizó elecciones, las de siempre, con candidatos únicos. Volvió también muy pronto a los inefectivos mecanismos ideológicos, como al desperdicio masivo y desorden típicos de la economía comunista. En mayo los partidarios de continuar los cambios, "revisionistas", fueron condenados en el pleno del CC, y algunos de ellos expulsados del partido después. En octubre se disolvió "Po prostu" ["Simplemente"], el semanal que constituía el símbolo de los cambios del año anterior. Gradualmente las autoridades se alejaban de los cambios, pero la etapa estalinista, la más dura de la dictadura, pasaba a la historia.

30. En su apogeo cubrían solamente el $6 \%$ de las tierras cultivadas.

31. Parece muy acertado el término de "une révolution canalisée" (F. FEJTÖ, Histoire des démocraties populaires. Après Staline. 1953-1968, Paris 1969, pág. 112). 


\section{Conclusiones}

El 28 de junio de 1956 unos 100.000 polacos salieron a las calles de Poznań para pedir Pan, Libertad y Dios, es decir Polonia libre. El estallido de la furia de los obreros fue espontáneo y causado directamente por la cada vez más desastrosa situación económica. Pero el significado de la revuelta fue sobre todo político, constituyendo la primera rebelión contra la autoridad comunista, odiada por la mayoría de los polacos, cuando todavía por las heridas y pérdidas del estalinismo a nadie se le ocurría presentar un programa positivo de cambio del sistema. Fue una protesta contra el terror del miedo y la miseria no tan famosa como las de Berlín de 1953, Budapest del mismo año o Praga de 1968, pero no menos importante. Fue una necesidad de sentirse libre a cualquier precio, aunque fuera tan solo por unas horas.

Los obreros de Poznań no tenían ni una ideología concreta ni unos líderes con ambiciones políticas o de liderazgo. No les dio tiempo. Lo único que la autoridad les permitió fue expresar su deseo de mantener su identidad nacional y religiosa, en este fenómeno poco entendido del catolicismo polaco -una especie de elemento patriótico y nacional, y en menor medida teológico-, un fenómeno relacionado con la Iglesia polaca, casi siempre perseguida y a menudo presente como un símbolo nacional.

Como se decía, "el pueblo entró al centro de la ciudad" para pedir la realización de sus derechos. Querían la soberanía de Polonia y la democracia. No solo pan. No existía entonces crimen más grande que declarar esos lemas. Fue un típico ejemplo de la situación revolucionaria, según la versión de Lenin. Los gobernantes ya no podían dominar del viejo modo y los gobernados ya no iban a aceptar los antiguos métodos de mando. Fue un signo de deslegitimización del poder del partido comunista, solo instalada sobre los tanques y el terror. Fue la primera vez que el partido se alejaba de los lemas que empezaron a ser materia de chistes -en muchos países de esta región europea-, como la "Dictadura del proletariado" o el "Gobierno progresista", bromeando sobre la terminología comunista, aunque la realidad fuera que continuaba en vigor el núcleo del lenguaje totalitario de la doctrina ${ }^{32}$. El proletariado de Poznań señaló a los dirigentes comunistas no como dictadores que violaban los derechos, sino como los dueños momentáneos de una Polonia que no les pertenecía, si no fuera porque estaban protegidos por los soviéticos. Los lemas de las pancartas expresaban

32. El estilo del discurso de la época comunista es un tema muy complicado, especialmente para los extranjeros que investigan la historia de Polonia de aquel periodo. La confusión terminológica creada al usar los comunistas las palabras "democracia", "libertad", "soberanía", "patriotismo" en un sentido y con unas definiciones muy alejadas del sentido tradicional, daba como resultado la creación de una lengua de alusión por parte de la oposición y el empleo de elementos del discurso oficial en la lucha contra la censura. 
mucho más: fuera los rusos, fuera los comunistas. Casi todos lo entendieron así. A nadie se le ocurría pensar en la posibilidad del mantenimiento de los comunistas en el poder sin la protección soviética. Otra cosa era que la omnipotencia de Moscú en el bloque parecía ser eterna, lo que daba esperanza en el poder de la ingeniería social, capaz de destruir la sociedad libre en unas generaciones creando un fenómeno Ilamado en la sovietología "homo sovieticus", en terminología empleada por el filósofo polaco, el Padre Józef Tischner ${ }^{33}$.

Los obreros de Poznań hablaron en nombre de toda Polonia. Así corrió fácilmente el rumor de que había levantamiento en todo el país. La insurrección no fue precedida por ninguna conspiración antisistema, ni imperialista, como decía la dictadura. No había tampoco "provocadores criminales", ni "subterráneo reaccionario". Los obreros saliendo de la fábrica no cogieron las armas que se encontraban en la fábrica; éstas se hicieron necesarias más tarde, cuando los asesinos de la seguridad sabían que no les quedaba otra opción que defenderse a mano armada porque si no, sus víctimas hubieran sido vengadas. Los poznanienses enfurecidos por los disparos presentaron una postura muy radical, que muchas veces desaparece en las descripciones de Poznań de 1956 centradas en la perspectiva de la tragedia de la represión armada. Pero el deseo del ajuste de cuentas con la dictadura comunista se convirtió de sueño en realidad en muy poco tiempo.

Desde entonces la dictadura que se autodenominaba "popular" siempre estaba atemorizada por las actuaciones obreras. Poznań de 1956 fue un choque para las autoridades, se temía el estallido de semejantes sucesos en todo el país. Tuvo además una importancia enorme porque, como demuestra la historia de los vecinos de Polonia, la dictadura comunista en su edición más opresiva podía durar todavía unos años más y la liquidación de la herencia del estalinismo podría ser mucho más lenta. Fueron los obreros de Poznań los que derrumbaron por su corta revolución los mecanismos de la etapa más sangrienta de la Polonia contemporánea, no contando las ocupaciones aparentes. Después de 1956, el sistema comunista nunca volvió al terror estalinista, no teniendo tampoco "la cara humana", pero sí "los dientes rotos" por los obreros de Poznań" ${ }^{\prime 34}$. El comunismo nunca volvió a ser fuerte, existiendo bajo el signo de que fue impuesto a Polonia por una potencia ajena, para muchos retrasando el progreso del país para una o dos generaciones.

Por otra parte, la batalla de 1956 en Polonia la ganó en algún sentido también la autoridad por el hecho de presentar los cambios necesarios para man-

33. J. TISCHNER, Etyka solidarności oraz Homo sovieticus [Ética de la solidaridad y el Homo sovieticus], Cracovia, 2005; ídem, Ética de la solidaridad, Madrid, 1983.

34. A. MICHNIK, Poznań przemówit w imieniu całej Polski [Poznań habló en nombre de toda la Polonia], en, Poznań był pierwszy. Czerwiec 1956 [Poznań fue primero. Junio de 1956], suplemento de "Gazeta Wyborcza" del 28 de junio de 2006. 
tenerse en el poder como una especie de liberalización que se vendía como más propia del sistema comunista que la época estalinista. La dictadura frenó la avalancha de la democratización, sobreviviendo el momento más crítico de cada autoridad "mala" y poco atractiva -según Alexis de Tocqueville, el momento del comienzo de su reforma-. 1956 fue en general un fenómeno sociológico consistente en recibir bien los cambios de un sistema totalmente represivo hacia una especie de dictadura muy severa y fuerte pero incomparable con lo anterior. Si a eso se añadía la preponderante amenaza y cautela por parte de los soviéticos y la disminución de la esperanza de la III Guerra Mundial, se obtenía un grado bastante alto del fatalismo de la sociedad polaca que duró hasta el año 1970.

La insurrección de Poznan' fue el principio de las revueltas obreras y otras protestas de la resistencia de la sociedad polaca contra el odiado sistema. Después de ese levantamiento le siguieron los de Marzo de 1968, Diciembre de 1970, Junio de 1976, Agosto de 1980 y Junio de 1989, cuando la autoridad disparaba a los obreros o no lo hacía por temor a su propia seguridad. La situación se repitió grosso modo dos veces: en diciembre de 1970 y junio de 1976, cuando los obreros salieron a la calle, queriendo hablar con la autoridad, pero ésta no consideraba el diálogo como un método de hablar con la sociedad, mandando la milicia y el Ejército contra los protestantes. La manifestación pacífica se convertía de esa manera en luchas con sus víctimas que pasaban a la historia.

En Poznań empezó el movimiento "Solidaridad" que llevó al derrumbe del comunismo. La salida de los obreros de "Cegielski" supuso en la tradición el primer elemento en la maduración de la protesta masiva que llevó a la creación de los sindicatos libres en Polonia en 1980, algo completamente contrario a la ortodoxia comunista, y después a la caída del comunismo primeramente en Polonia. Pero fue una rebelión más radical, más antisistema de todas las que ocurrieron entre 1956 y 1989. Después de 1956 la insurrección armada ya no se repitió nunca hasta la caída del sistema. Poznań fue la primera y última prueba de luchar a mano armada contra los comunistas. Fue el último levantamiento en la historia de Polonia. Muy corto, espontáneo y efímero, pero una continuación de las actividades de los años cuarenta del subterráneo independentista, algo parecido a las protestas obreras postreras, porque muchos de los que participaban en los sucesos del 28 de junio creían en un levantamiento nacional. Además, después de 1976 se llegó a la convicción del deber de no quemar los comités del partido, sino "crear los suyos". Así, en agosto de 1980 los obreros que declararon la huelga de ocupación, no salieron de sus lugares de trabajo. La lección fue que derrumbar al comunismo sólo se iba a poder realizar usando las armas no violentas, debilitándolo desde dentro. A pesar de esto, en 1980 y 1981 el movimiento de "Solidaridad" hundía sus raíces en Junio de 1956 y no en Octubre. Se elegía más un movimiento libertario de lo que se consideraban unos acontecimientos muy relacionados con el cambio del partido mismo. Sin embargo, hasta el final del comunismo se mantuvo la situación: 
donde más obrera era la resistencia, más carácter anticomunista Ilevaba. Eso fue desastroso para el poder, atacado desde su teórica base ideológica.

Los comunistas conocían el peligro de la memoria de Poznań de 1956, de una revuelta contra el totalitarismo. Si ya se les forzaba, la llamaban "inquietudes", "sucesos", "alteraciones", para no decir "rebelión" o "insurrección". El levantamiento poznaniense no existía en los manuales de historia. Sobrevivió en la tradición, en los poemas, en las publicaciones subterráneas. Cuando estaIló "Solidaridad", estalló también la memoria sobre el levantamiento obrero que se convirtió en el símbolo de valentía y protesta contra la esclavitud. En 1983 las autoridades rechazaron decididamente la posibilidad de introducir en el programa de la peregrinación del Papa Juan Pablo II a Polonia una oración ante las Cruces de Poznań, el gran monumento que después de años de silencio sobre la tragedia se construyó bajo la presión de "Solidaridad" tres años antes. También este símbolo se convirtió en un lugar especial para la oposición democrática, siendo sus alrededores el escenario, dos años más tarde, de la paliza hasta la muerte a dos jóvenes por las unidades especiales antidisturbios ZOMO, o el lugar donde por depositar flores y encender lamparillas se perseguía a los culpables en los juzgados.

Sin junio no habría Octubre de 1956, aunque este último, llevado a cabo ya en un ambiente de fermento por la inteligentsia, fue por eso mejor conocido, descrito y más famoso. A la historia pasaron sobre todo las moderadas actuaciones del otoño de los reformistas intelectuales, muy debilitados y desangrados por los horrores de la guerra y del estalinismo, pero menos la universal retórica antisistema y anticomunista de las protestas de toda Polonia. Así, Poznań de 1956 se silenció muchos años no sólo por las autoridades, sino también por una parte de los intelectuales polacos que actuaban o por su bien o por el realismo relacionado con el lema "Hagamos lo nuestro". No querían provocar a la autoridad que después de 1956 ya no era tan totalitaria, pero guardaba el azote de una posible movilización de las fuerzas de seguridad y el Ejército contra la sociedad que no tenía ningún derecho de opinar, salvo declaraciones dentro del marco establecido por el partido de la dictadura. Así, de las dos posibilidades, el insurreccionismo y el gandismo, los intelectuales, pero también sobre todo los obreros, eligieron con pocas excepciones la segunda que en un momento dado, en los años ochenta, tuvo éxito. Emplear entonces la fuerza espontánea como en 1956 hubiera sido muy malo para la causa polaca y para la causa del establecimiento de la democracia en la zona, dado el poder manipulador de la propaganda moscovita tanto más exitosa en Europa Occidental cuanto más lejos se encontrara el país de su acción. Y aunque el símbolo del derrumbe del comunismo no es ningún elemento de la historia de Polonia, fue la primera en derrocar el sistema, siendo la llamada "caída" de muro de Berlín nada más que una consecuencia de la situación en otros países del bloque que no dejaron dudas de que ya nadie iba a defender el muro. Así se le pudo destrozar a pedazos y pasar de una manera espontánea de una parte de Berlín a la otra. 
Realmente, el comunismo cayó ya en 1980, cuando ocurrió el carnaval de libertad ganado por los obreros de los astilleros de Gdańsk. Por más de un año el sistema fue prácticamente controlado por la sociedad, lo que fue destrozado por el general Jaruzelski al declarar el estado marcial que costó la vida a cerca de cien personas, o como decían muchos cuando "el estado declaró la guerra a la sociedad". El proceso ya no se detuvo y después de las elecciones de junio de 1989 se formó en Polonia el primer gobierno no comunista en Europa Centro-Oriental. Capitularon las fuerzas del viejo y anacrónico régimen "progresista" de una manera muy inteligente, convirtiéndose de un día para otro al grupo de partidarios de la democracia, liberalismo, capitalismo, Europa unida, alianza con los Estados Unidos y todas las actuales tendencias del Occidente, según las exigencias de la época y del momento. Pero eso ya pertenece a la historia de otra Polonia, libre, antitotalitaria y democrática, que sabe muy bien lo que debe a los tres junios "de libertad" de 1956, 1976 y 1989, ya que los dos últimos no hubieran ocurrido sin la revuelta de Poznań. 